\title{
The Meaning Construction of Idiom Based on Blending Model
}

\author{
Han Jianghua * \\ (Sichuan University, China)
}

\begin{abstract}
This paper studies and construes the meaning construction of idiom based on blending model, intending to use the blending model to reveal the meaning construction mechanism of idiom so as to make people understand that the meaning of idiom is constructed through the non-compositional integrated approach. The study shows that the conceptual blending is a primary means of encoding the metaphorical meaning of idiom. It blends the concepts of different cognitive frames, through the cross-space mapping and projection, to form a new concept, which is the metaphorical meaning of idiom. The process of idiom's meaning construction is essentially a semantic leap, thus, a process of frame-shifting. Moreover, the national cognitive and cultural models play a very important role in the process of meaning construction of idiom. The cognitive model provides a guiding for the meaning construction of idiom, and this guiding become a kind of reality induced by the cultural model eventually.
\end{abstract}

Keywords: idiom, meaning construction, blending model

\section{Introduction}

Language is a symbolic system that people use for social communication. A certain language often belongs to a certain ethnic group, and is used by people in various social backgrounds and lots of discourse. The more people use the language, the possibility of change of language will be greater. The development trend of language is that the structure will be from simple to complex and its expression ability will be from poor to rich and precise (Wang, 2017:233-268). In this process, a marked characteristic is that a large number of idioms generated and be widely used in daily communication. The generation of idiom is not only the result of language development, but also the result of the artistic expression of people's understanding and experience of the real word in daily life. These idioms are not only the marker which represents the ability of expression of language become richer and more precise, but also is an aggregation of cognition of a certain ethnic

\footnotetext{
* Dr. Han Jianghua: Associate Research Professor of Linguistics, College of Literature and Journalism, Sichuan University, Chengdu City, Sichuan Province, China. This study is funded by Huohua Innvation Project of Sichuan University (No: 2018hhs-38). E-mail: hanjianghuathai@ sina.com.
} 
group.

The idiom refers to a set expression of two or more words, which has a fixed structure and means something other than the literal meanings of its individual words; we cannot change the compositions of idiom arbitrarily and cannot analyze its structure through the general rules of word-building (Jiang, Tan \& Cheng, 2016: 1214). "People use idioms to make their language richer and more colorful and to convey subtle shades of meaning or intention. Idioms are used often to replace a literal word or expression, and many times the idiom better describes the full nuance of meaning. Idioms and idiomatic expressions can be more precise than the literal words, often using fewer words but saying more." (Brenner, 2003:4)

So, study the meaning construction of idiom, does not only help us to understand the features of idioms, but will also help us to explore the cognitive model of a certain ethnic group.

However, we cannot analyze the meaning construction of idioms through the general rules of word-building, because the meaning construction of idiom is nonlinear.

And the conceptual blending, as Fauconnier and Turner (1998) pointed out, is a group of non-compositional processes, and in this process, the thought ability of meaning construction is evoked, thereby generating emergent structure. Therefore, using the conceptual blending model to analyze the meaning construction of idioms will help us to understand the meaning of idiom better. For this point, in this paper, we will use the conceptual blending model to analyze the meaning construction of idioms.

\section{Blending view of meaning construction based on blending model}

Cognitive semantics understands semantics as the relationship among objective world, human cognition and language symbol (Li, 2008:77; Klapper, Dotsch, Rooij, et al., 2018). Therefore, the language meaning does not directly connect with the real world, but connects with the human mind. People learn about the real world through experience and cognition, and then form conceptual structures in the brain which generate meaning. Language expression is the representation of mental experiences ( $\mathrm{Xu}, 2007)$. Thus, the human mind is the bridge between semantics and real world. Language expressions, thus, do not have any meanings; they are prompts for us to construct meanings by working with processes we already know (Turner, 1991:206; Zbikowski, 2018). Outside of the specific language environment, any language expression is uncertain. When we understand an utterance, we in no sense are understanding "just what the words that we say"; the words themselves say nothing independent of the richly detailed knowledge and powerful cognitive processes we bring to bear (Turner, 1991:206; Han, 2017). In order to express a 
The Meaning Construction of Idiom Based on Blending Model

clear meaning, the language expression must be linked with the encyclopedic knowledge in the human mind. Therefore, the construction of meaning is open-ended (Turner, 1991:206; Han, 2018).

At the same time the understanding of language meaning cannot rely solely on linguistic knowledge, but also must rely on encyclopedic knowledge as well as experience-based reasoning. However, linguistic knowledge is only the input of reasoning. Therefore, the understanding of the meaning is a process of conceptualization which is completed in the human brain through the cognitive operation of blending among linguistic knowledge, encyclopedic knowledge, and experience-based reasoning. As Turner (2002) pointed out, semantics is a connection spanning more than one mental space. Moreover, language meaning is not statically stored in the human mind, but is rather an active and living presence. Moreover, the meaning of language is also not limited to fixed mental material in the human mind, but rather it is generated after a series of cognitive operations. The generation of the meaning of language in the human mind needs to blend information from different mental spaces through the cognitive operations of mapping, projection, and connection among others. In this respect, Fauconnier $(1994,1997)$ proposed using mental space theory and conceptual blending theory to explain the process of people's categorization constructing Cognitive Model, and understanding the meaning of natural language. In the monographs Mappings in thought and language (Fauconnier, 1997) and The way we think: Conceptual blending and mind's hidden complexities (Fauconnier \& Turner, 2002), Fauconnier and Turner have made a comprehensive interpretation for the conceptual blending theory, and these results further improve the theoretical content of semantic view based on "blending".

The semantic view based on "blending" believes that any presentation of the language expression represents a concept, which is activated in the brain of speaker and hearer. New meaning is generated in the dynamic process of the adaptation of discourses and blending in certain contexts. The discourses, as the input information that guides and limits the generation of meaning, activates long-term memory information upon entering the human mind; this forms temporary concept sets, namely, mental spaces. Based on the conceptual blending mechanism, these mental spaces will generate emergent structure through cross-space mapping, projection, and compression among others, so as to achieve the construction of meaning. In other words, conceptual blending is a basic means to construct meaning of natural language. The conceptual blending network, which is based on mental spaces, reveals the dynamic process of the construction of meaning in natural language from the cognitive perspective. So the conceptual blending model provides us a new perspective for processing the construction of meaning in natural language. In this view, 


\section{Han Jianghua}

meaning is not "in" language; rather, language is like a recipe for constructing meaning - a recipe that relies on a lot of independent cognitive activity (Fauconnier, 1994:2-5; Saeed, 2004:364-373). The details of conceptual blending processes are shown in the following diagram:

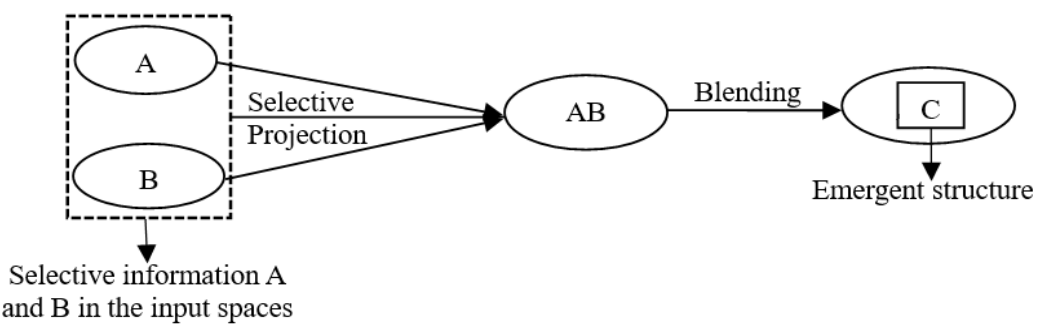

Figure 1. Conceptual blending processes

\section{Conceptual blending and meaning construction of idiom}

The conceptual blending model is not only emphasis on the role of context, but also can reveal the dynamic process of the meaning construction from the simple spatial structure (Coulson \& Oakley, 2005). It explains the space mechanism of dynamically generating of meaning. It also can explain the dynamic, random, and fuzzy thinking and cognitive activities effectively.

While, the meaning construction of idiom is nonlinear because the formation of idioms is the result of the conceptual blending. In other words, the conceptual blending is a main means of forming the metaphorical meaning of idiom. It blends the concepts, which come from different cognitive frames, through the cross-space mapping and projection to form the new concept; namely, the metaphorical meaning of idiom.

\subsection{Highlighting and hiding: trade-offs in conceptual blending}

In the conceptual blending, not all but only some elements of the input spaces are projected onto the blending space to participate in the formation of the emergent structure. This is the highlighting and hiding in the conceptual blending. In the process of conceptual blending which elements are highlighted and which elements are hidden will be decided according to the target of the conceptual blending. The elements that will help to express the new concept which is formed in the blending space, will be highlighted. On the contrary, the elements that have nothing to do with the new concept which is formed in the blending space, will be hidden. Such as in the conceptual blending of idiom (1), the input space I involves a lot of elements, such as: dog in Sichuan, kind of dog, cognitive ability of dog, sun, rarely see the sun, place, action of bark at the sun, a lot of fog, time, and so on; and the input space II involves the following elements: An ignorant person, gender, age, see some uncommon things, kind of things, feel strange, place, time, etc. But in the whole 
conceptual blending, only part of these elements involved in the two input spaces are projected onto the blending space to participate in the formation of the emergent structure and are highlighted. The elements which are highlighted are as follows: dogs in Sichuan, cognitive ability of dog, rarely see the sun, action of bark at the sun; ignorant person, see some uncommon things, feel strange. And the other elements, such as: kind of dog, kind of things, gender, age, place, time, etc., are hidden because that they do not participate in the formation of the emergent structure in the blending space.

$$
\begin{aligned}
& \text { (1) } s u^{214} t_{6}^{h} u a n^{214} \mathrm{fei}^{51} \quad z i^{51} \quad \text { (蜀犬吠日) } \\
& \text { Sichuan area dog bark sun } \\
& \text { 'An ignorant person makes a fuss about sth. which he alone finds.' }
\end{aligned}
$$

The elements of the two input space that are highlighted in the conceptual blending are the ones that have some similarity and can make contribution to the emergent structure in the blending space. Such as in the conceptual blending above, dog in Sichuan and ignorant person share the feature of agent; dog feels strange to the appearance of the sun and ignorant person feels strange to the things never see before share the feature of patient, etc. The conceptual blending is based on commonalities ( $\mathrm{Li}, 2008: 174$; Han, 2018); the elements that do not have common features often cannot make their own contribution to the conceptual blending, so they will be hidden.

\subsection{Inside and outside of language: Implied background in conceptual blending}

The conceptual blending, which complete under the guiding of cultural models and cognitive models, wanting to be fully understood by people eventually, often need to evoke the hidden relevant background knowledge. Without this background knowledge, the emergent structure that forms in the blending space will be difficult to understand. Such as the conceptual blending in the idiom (2), the background knowledge which needs to be evoked is that the story of Li Gui impersonate Li Kui in the Chinese classic novel Shui Hu Zhuan.

$$
\begin{aligned}
& \text { (2) } \mathrm{Li}^{214} \mathrm{Kuei}^{214} \quad \mathrm{ju}^{51} \quad \text { (李鬼药) } \\
& \text { Li Gui (a person) medicine } \\
& \text { 'a potentially life-threatening fake medicines' }
\end{aligned}
$$

In the novel Shui Hu Zhuan, Li Kui and Li Gui are two different characters. They are mortal enemies: Li Kui is a hero praised by everyone, and delivers the poor and all those who are oppressed; Li Gui is a furry thief cast aside by the world, and rob at everywhere. In order to pull the banner as a guise, and also in order to facilitate to do all kinds of evil, Li Gui impersonate as Li Kui: Smearing ink on the face and holding two axes in order to make himself like Li Kui so as to pose as Li Kui to rob. However, no story without coincidences, when the fake Li Kui (Li Gui) met real Li Kui, he immediately appears the true face. 
For this reason, Chinese people take the name Li Gui as synonym for fake products in daily life. Nowadays, driven by economic interests, there are a lot of fake drugs in Chinese market. These fake drugs caused a lot of harm to society. Thus forming the idiom (2). It refers to the products confused as real ones, looks like drugs, but in reality as ordinary food or disinfectant (Baidu Baike Dictionary, 2019, para. 1). In this conceptual blending, fake drugs and Li Gui have a common feature that is to impersonate other good entities, leading unworthy of the name.

\section{Conceptual blending and frame shifting: Semantic leaps in the meaning construction of idiom}

As mentioned earlier, idiom is the fixed language expression unit, which is formed in the process of conceptual blending, means something other than the literal meanings of its individual words. Therefore, the idiom is not the inherent expression unit of language, but has a complicated formation process. And the process of its formation has a series of semantic operations. In the beginning of the formation, these language units have their own inherent literal meaning. When people use these linguistic units in daily communication, they give these units metaphorical meaning which are more expressive than the literal meaning through the cognitive method of conceptual blending. From then on, these units have the dual semantics, namely literal and metaphorical meanings. When the metaphorical meanings of these language units are immobilized, these language units became the idioms. The process of formation of idiom is essentially a semantic leap, and the process is a process of frame-shifting, and the conceptual blending is the main method achieving the frame-shifting and semantic leaps.

\subsection{Frame-shifting I: Generating metaphorical meaning}

Giving a certain language unit, a metaphorical meaning through the conceptual blending will inevitably lead to frame-shifting. In the original framework, the element, which is selected to participate in the meaning construction, is the literal meaning of these linguistic units. In this frame, metaphorical meaning is entirely useless. Only when leaping out of the existing semantic frame, and shifting to a new semantic frame, the metaphorical meaning will be selected to participate in the meaning construction, so as to achieve the value in the semantic construction. Here, let us take the idiom (3) as an example. Its literal meaning is an apparatus, which is forged by gold and be used to hold rice. This literal meaning involves a food apparatus framework. In this framework, involving bowls, plates, pots, rice, dishes, chopsticks, eating, etc. In this framework, each word has its referent entity. The definition of the meaning of each word is based on this frame. Once leave this frame, the meaning of these word cannot be clearly defined and categorized. But when people give the language unit (3) a metaphorical meaning through the conceptual blending in the daily 
language using, the language unit (3) has a semantic frame-shifting. The metaphorical meaning of (3) refers to a job that has excellent pay. This metaphorical meaning obviously does not fit the original frame. The referent of metaphorical meaning is job, which involves another semantic frame that is the frame of work. In this frame, it involves work, workers, salary, workplace, job content, the nature of the work, and so on. Only implanted them in the frame of work, they can be cross-referenced and defined to each other. Leaving this frame will be hard to give an accurate definition.

$$
\begin{aligned}
& \text { (3) } \operatorname{tgin}^{55} \operatorname{fan}^{51} \operatorname{wan}^{214} \text { (金饭碗) } \\
& \text { golden rice bowl } \\
& \text { 'high-paying position' }
\end{aligned}
$$

\subsection{Frame-shifting II: Lead to a reorganization of the semantic system}

Giving a certain language unit a metaphorical meaning through the conceptual blending will let this language unit be implanted into a new semantic frame, and this will lead to a semantic adjustment within the semantic system inevitably. Because that before the formation of the metaphorical meaning of the idiom, the language has already existed the inherent unit which expresses the same meaning with the metaphorical meaning of the idiom. After the formation of the metaphorical meaning of idiom, there exists a situation that the idiom and the inherent unit express the same meaning. This violates the economic mechanism of language. In order to comply with the economic mechanism, the idiom and the inherent unit will adjust the semantics through a semantic using. For example, both the idiom (3) and the phrase (4) refer to a job which has excellent pay. After both of them adjusting the semantics through a semantic using, they will be used in different fields. Nowadays, the idiom (3) is generally used in spoken language, literary works, news reports, and so on, implying an informal means; however, the phrase (4) is generally used in laws, regulations, government documents, and so on, reflecting a solemn.

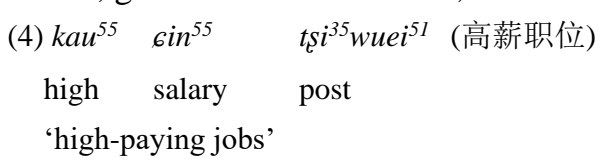

\subsection{Frame-shifting III: A cognitive and cultural orientation}

The conceptual blending is the main method to achieve the frame-shifting and semantic leaps in idiom. The cognitive model provides a guiding for the conceptual blending, and this guiding become a kind of reality induced by the cultural model eventually. In other words, cognitive and cultural model play a very important role in the whole process of conceptual blending. Frame-shifting, which is achieved based on conceptual blending, has an inextricably link with the cognitive and cultural model naturally. Semantics shifts from one frame to another frame, the participation of cognition and culture cannot be ignored. Based on this, it can be said that cognition and culture is the induced factors of the 


\section{Han Jianghua}

frame-shifting.

For example, to express the meaning of deceive oneself, the Chinese uses the idiom (5), the Thai uses the idiom (6), and the English uses the idiom (7). All of these idioms form the metaphorical meaning through frame-shifting based on conceptual blending. The reason why they choose different original source frameworks is because of the different cognitive models and cultural models of their respective nation. If we interchange these original source frameworks, it will seriously affect the formation and expression of metaphorical meanings, because the interchanged source framework will violate the cognitive and cultural orientation principles in frame-shifting.

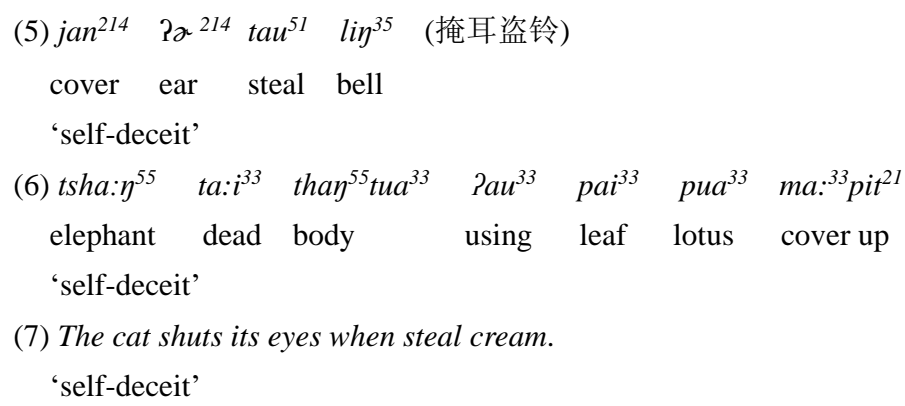

\subsection{Semantic leaps: The realization of frame-shifting}

"Semantic leaps is not a technical term, but rather a family of interesting natural language phenomena. It includes all sorts of nonstandard meanings absent from dictionaries and, typically, not computable by traditional parsers." (Coulson, 2001:2) The semantic leaps in idioms mainly refer to the semantics of idiom shift from literal to metaphorical meanings. The metaphorical meaning of idiom cannot analyze from the literal meaning through the traditional methods, because this is a non-compositional phenomenon. From the literal meaning to metaphorical meaning, there is no slow transition, but a direct leap. Sometimes, it is hard to find the contact between the literal and metaphorical meanings. Although, sometimes there exists some contact between the literal meaning and metaphorical meaning, but the relevance is not so obvious.

For example, the Chinese idiom (8), its literal meaning refers to long sleeves will help one to dance skillfully. However, through a conceptual blending mechanism, it is given a metaphorical meaning, referring to a person who is good at playing tricks or has great wealth and high power could do things easily. It is very difficult to find the contact between the literal and metaphorical meanings of this idiom. It is a semantic leap completely. It is difficult for us to departure from the meaning of "long sleeves will help one to dance skillfully" to get the meaning of "a person who is good at playing tricks or has great wealth and high power could do things easily" through the traditional method of semantic analysis. The generation of this semantics is a non-compositional process. This process completes 
through the conceptual blending, which form an emergent structure in the blending space, and evoke the long-term memory factor. At last achieve the semantic leap through the completion and elaboration.
(8) $\operatorname{tsan}^{214} \operatorname{ciou}^{51}$
$\operatorname{san}^{51} \quad w u^{214}$ (长袖善舞)
long sleeve
good at dance

'a person who is good at playing tricks or has great wealth and high power could do things easily'

\subsection{A summary of the meaning construction process of idiom based on blending} model

Through the above analysis, we can clearly see the process of meaning construction of idiom based on the blending mode and all aspects that are involved in the meaning construction process of idiom. At here, we will summarize the meaning construction process of idiom based on blending model as the following diagram:

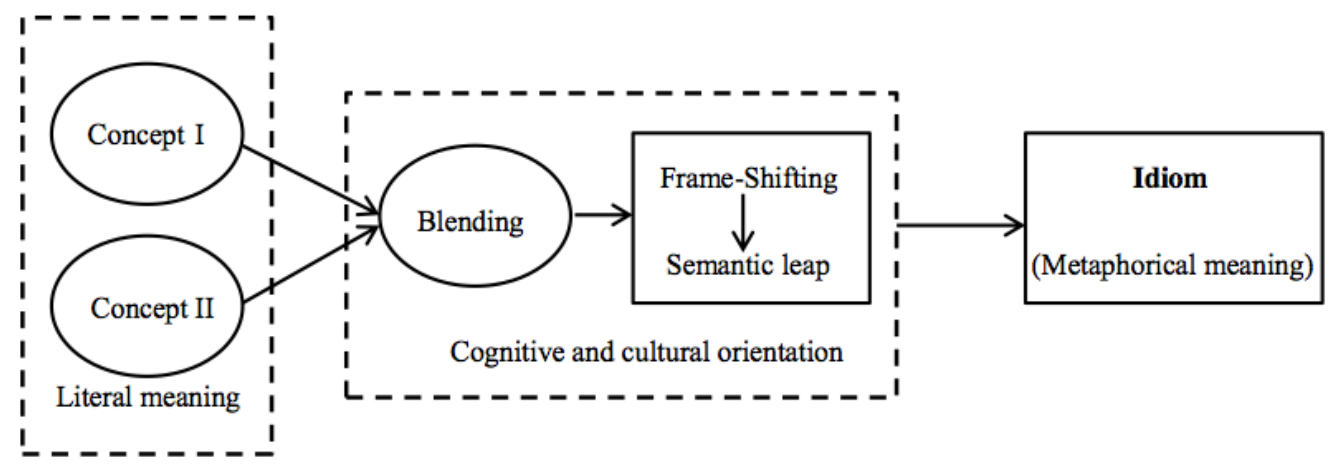

Figure 2. The meaning construction process of idiom based on blending model

\section{The blending models in the meaning construction of idiom: A case analysis}

At here, we will use the Chinese idiom (9) as an example to analyze the meaning construction process of idiom based on blending model.

(9) $t_{S} h a u^{214} j o u^{35} j y^{35}$ (炒魷鱼)

fry squid

'be dismissed'

In China, due to the vast territory and large population, a lot of people go to work far from home. In the era of poor transportation systems, it would take a long time to come back home from the work place. So many people cannot come back home every day. For this reason, almost all of the work units would provide accommodation for the staff. And the staffs need to bring their own bed linen to the dormitory. If the employees were dismissed, employees had to pack their own bed linen and leave the staff quarters.

In the past, Chinese people did not use a travel bag or a suitcase to hold things. For the 


\section{Han Jianghua}

convenience and saving, the employees would put towels, clothing and other valuables things in the middle of the bedding, with bedding rolled up and bundled, then took them home.

In Chinese cooking, when making a fried squid, every squid pieces is rolled slowly from a flat shape into a cylindrical shape. This change of the squid is very similar to the process of the employees rolled up the bedding and takes it away from the unit staff quarters when dismissed. Hence, through comparison of the process of fried squid with the dismiss of employees, Chinese people construct the idiom (9), which refers to the employee is dismissed by the work unit.

In the idiom (9), the two input spaces have the different frame, the input space $I$ is cooking frame, and the input space II is the dismissal frame. The cooking frame of the input space I is projected onto the blending space and extend to the organizational frame of the blending space.

In the conceptual blending of idiom (9), it uses squid to map staff, fried the squid to map the employee is dismissed, squid is rolled up to map the staff packs things and rolled up the bedding, take the squid away from the pan to map the employee forced to leave the work unit, etc. The process of the elements of the two input spaces is projected onto blending space to conduct the conceptual blending is shown in the following diagram:

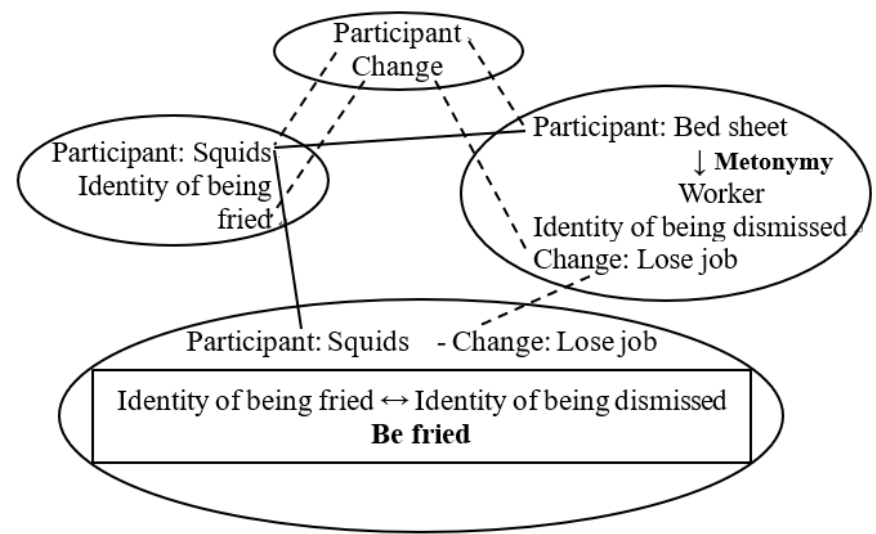

Figure 3. Conceptual blending diagram of idiom (9)

In the conceptual blending net-work of this idiom, the organizational frame of the input space I is projected onto the blending space, and form the emergent structure through the compression of the key relationships. It uses the fried squid and the change of the squid during the cooking process to show the phenomenon of employee is dismissed by the work unit. Conversely, the organizational frame of the input space II did not participate in the formation of frame of the emergent structure in the blending space. 
The Meaning Construction of Idiom Based on Blending Model

\section{Conclusion}

Through the analysis above, we can know that the conceptual blending is the main method of the formation of idioms. Idioms generated by forming the metaphorical meaning through the conceptual blending. So, in order to understand these idioms accurately, we should understand the conceptual blending which is involved in the idioms firstly. And the process of formation of idiom is essentially a semantic leap, and the process is a process of frame-shifting, and the conceptual blending is the main method achieving the semantic leaps and frame-shifting. In addition, national cognitive and cultural model play a very important role in the whole process of meaning construction of idiom.

\section{References}

Bai Wanru. 2000. Guangzhou Dialect Dictionary [M]. Nanjing: Jiangsu Education Press.

Bao Houxing, Cui Zhenhua, Shen Ruoyun, Wu Yunji. 1998. Changsha Dialect Dictionary [M]. Nanjing: Jiangsu Education Press.

Baidu. 2019. Baidubaike Dictionary: Li Gui medicine [OL]. Retrieved from https://baike.baidu.com/item/ 李鬼药/12763595? fr=Aladdin.

Brenner, G. 2003. American Idioms Handbook [M]. Indianapolis: Wiley Publishing.

Coulson, S. 2001. Semantic leaps: Frame-shifting and conceptual blending in meaning construction [M]. Beijing: Foreign Languages Teaching and Research Press.

Coulson, S. \& T. Oakley. 2005. Blending and Coded Meaning: Literal and figurative meaning in cognitive semantics [J]. Journal of Pragmatics, 37(10): 1510-1536.

Fauconnier. G. 1997. Mapping in Thought and Language [M]. Cambridge: Cambridge University Press.

Fauconnier, G. \& M. Turner. 2002. The Way We Think: Conceptual blending and the mind's hidden complexities [M]. New York: Basic Books.

Fauconnier, G. 1994. Mental Spaces: Aspects of meaning construction in natural language [M]. London: Cambridge University Press.

Fauconnier, G. \& M. Turner. 1998. Conceptual Integration Networks [J]. Cognitive Science, 22(2): 133-187.

Han J. H. 2017. The function of poetic metaphor: Taking the poetic metaphors expressing characters' emotions in A Dream of Red Mansions as examples [J]. Quarterly Journal of Chinese Studies, 5(2): $1-12$.

Han J. H. 2018. Conceptual Blending Analysis of Dian'gu (Classic Allusions) in A Dream of Red Mansions [J]. MANUSYA: Journal of Humanities, 21(2): 52-71.

Jiang, L. S., J. C. Tan \& R. Cheng (eds.) 2016. Modern Chinese dictionary [M]. Beijing: The Commercial Press.

Klapper, A., R. Dotsch, I. V. Rooij \& D. H. J. Wigboldus. 2018. Social Categorization in Connectionist Models: A conceptual integration [J]. Social Cognition, 36(2): 221-246.

Li, F. Y. 2008. An Introduction to Cognitive Linguistics [M]. Beijing: Peking University Press.

Saeed, J. 2004. Semantics (Second edition) [M]. London: Blackwell Publishing Ltd.

Turner, M. 1991. Reading Minds: The study of English in the age of cognitive science [M]. Princeton: Princeton University Press.

Turner, M. 2002. The Cognitive Study of Art, Language, and Literature [J]. Poetics Today, 23(1): 9-20.

Wang, Y. X. 2017. A Course Book of Linguistics [M]. Beijing: China Minzu University Press.

Xu, S. H. 2007. Model-based Pragmatic Reasoning: An outline [J]. Foreign Language: Journal of Shanghai Foreign Language University, 17(3):2-9.

Zbikowski, L. M. 2018. Conceptual Blending, Creativity, and Music [J]. Musicae Scientiae, 22(1): 6-23. 